\title{
Self-Adaptive Relaying Scheme of Reclosers for Fuse Saving in Distribution Networks with DG
}

\author{
Sadegh Jamali ${ }^{*}$ and Hossein Borhani-Bahabadi ${ }^{1}$ \\ ${ }^{1}$ Centre of Excellence for Power System Automation and Operation, School of Electrical Engineering, Iran \\ University of Science and Technology, Tehran, Iran \\ Email: sjamali@iust.ac.ir
}

\begin{abstract}
With growing penetration of distributed generation (DG) in electrical distribution networks (EDNs), miscoordination between fuse and recloser is more likely. This is the result of change of direction, as well as the magnitude of the fault current in the presence of DG where fuse saving cannot be achievd with standard recloser characteristics. This paper proposes a self-adaptive relaying scheme of reclosing operation for fuse saving in EDNs with DG. The recloser is programmed with a new non-standard characteristic using only the local voltage and current magnitude measurements. The proposed relaying scheme is tested for various fault conditions in a $20 \mathrm{kV}$ Iranian radial EDN containing DG units at different locations. It is shown that the proposed scheme is not affected by the presence of DG units whereas the conventional relays fail the protection coordination. The proposed characteristic maintains proper recloser-fuse coordination for all fault types and different DG conditions.
\end{abstract}

Keywords: Fuse saving, distributed generation, electric distribution network, non-communication protection, self-adaptive relaying scheme

\section{Introduction}

Fuse saving is a common protection strategy that prevents nuisance fuse blowing during transient faults by fast operation of the recloser located at the head of a feeder before the blown up of its downstream fuses. After a predefined time, enough for the fault clearance, the recloser reenergises the feeder and restores the power supply. Since $50 \%$ to $80 \%$ of faults occurring in electrical distribution networks (EDNs) have transient nature [1], the fuse saving strategy can improve the system security and reliability.

By incorporation of distributed generation (DG) units in EDNs, the fault current level and direction can change and cause miscoordination between the recloser and its downstream fuses. The fault current passing through the recloser decreases and at the same time the fuse fault current increases because of the DG contribution to the fuse fault current [2]. Therefore, the fuse may blow up before the fast operation of the recloser.

Several methods are presented in the literature for fuse-recloser coordination in the presence of DG. In $[3,4]$ a complete study is carried out on a test EDN to find the best DG locations and also the best recloser setting to minimise the loss of coordination between the fuse and the recloser under different fault conditions. In order to achive the best location and size of DG, different cases must be studied by changing DG size and location for each possible fault location. This method needs to be tailored for each EDN individually. In addition, any change in the number of DG units, can cause a miscoordination between the recloser and fuses. Thus, it may be very time consuming or even infeasible to find the best DG location and related recloser setting for large EDNs.

The method of [5] uses power electronic switches to disconnect all DG units after a fault inception and before any fuse blow up. This method does not require any upgrade of the protection system but under transient faults it disconnects DG units that may lead to the loss of production for several hours incurring costs [2]. In addition, a very fast fault detection and communication infrastructure is required for implementation of this method. 
Equipping the recloser with both inverse time and instantaneous overcurrent characteristics is proposed in [6]. This method uses an algorithm to calculate the pickup current setting of instantaneous element based on the number and location of DG units in EDN, to ensure fuse-recloser coordination under different fault conditions. The pickup current of the instantaneous element changes whenever a DG unit is added or removed from the network to ensure the required margin is maintained between the fast stage of the recloser operation and the fuse operation. Therefore, the method requires updating DG units status through communication links for correct relay setting.

Use of fault current limiter (FCL) to limit the fault current contribution of DG is proposed in [7-10]. FCL is located at DG terminals to reduce short-circuit currents to acceptable levels. The size of FCL is an important parameter that must be determined. In addition, a complete generator stability study must be carried out when FCL is used on DG terminals. The fault current limitation scheme depends significantly on the the fault current contribution of each DG unit, as well as the characteristic of the FCL device.

A method for limiting the DG fault current contribution based on the generator field discharge is proposed in [11]. In this method, a solid-state switch-based field discharge circuit is used that limits DG fault current, and decreases the impact of DG on EDN protection. According to the results of this method, the generator field winding must be able to withstand overvoltages up to 20 times of its nominal voltage.

A method based on managing the fault current contribution of synchronous DG units through the modification of inverter-based DG current phase angle under fault conditions is presented in [12]. For implementation of this method, voltage and current phasors of EDN elements are used for required control actions. Therefore, EDN must be equipped with smart meters. In order to utilise this method, existing of the inverter-based DG in EDN is necessary.

An adaptive method based on multiplying the recloser time dial setting (TDS) by the recloser to fuse current ratio is proposed in [13-15]. By modifying the TDS of the recloser fast operation using this ratio, the recloser fast characteristic is shifted downwards from its original characteristic. This increases the coordination time interval between the recloser and fuse. In order to implement this method, measurement units are required at all fuse locations and the current magnitude should be sent to the EDN control centre.

Utilising of the above methods for fuse saving in EDN with DG units requires a communication infrastructure. Otherwise, they can only be applied in specific networks.

This paper proposes a self-adaptive relaying scheme for fuse-recloser coordination in EDN with DG units that does not require any communication link and can be applied for any type of EDN. The proposed scheme is based on a new non-standard characteristic that uses only local voltage and current magnitude measurements. Nowadays, all the digital protective devices are microprocessor based and thus the reclosers can be programmed with the proposed characteristic.

The rest of the paper is as follows: conventional fuse saving strategy is presented in Section 2. In Section 3, the proposed recloser characteristic is explained. Section 4 presents the test EDN. The simulation scenarios and results are described in Section 5. Section 6 discusses the results, and the conclusion is drawn in Section 7.

\section{Conventional Fuse Saving Scheme}

In radial EDNs, fuses are located at the head of laterals to isolate the faulted lateral from the sound sections. Since most of EDN faults are transient, in order to save the fuse under transient faults, the fuse-recloser coordination is performed.

After a fault inception, the fast operation of the recloser should be set to save its downstream fuses involved with the fault. This practice is known as a fuse saving strategy, which can save expensive fuse replacement and avoid extended customer outage time following transient faults.

Fuses and reclosers use inverse current-time characteristics for protection coordination. In the fuse saving strategy, the recloser is equipped with an extremely inverse time overcurrent element given by $[16]$ : 


$$
t_{\text {recl }}=\left[\frac{28.2}{\left(\frac{I_{s c}}{I_{\text {set }}}\right)^{2}-1}+0.1217\right] \times T D S
$$

where $T D S$ is the time dial setting in fast or slow mode of the recloser operation, $I_{s c}$ is the recloser fault current, $I_{\text {set }}$ is the relay current setting, and $t_{\text {recl }}$ is the operating time of the recloser.

The general equation of the fuse current-time characteristic is [3]:

$$
\log \left(t_{\text {fuse }}\right)=a \times \log \left(I_{s c}\right)+b
$$

where $I_{s c}$ is the fuse fault current, $t_{\text {fuse }}$ is the operating time of the fuse, and the coefficients $a$ and $b$ are calculated by curve fitting. The constant $a$ is the slope of the straight line on $I^{2} t \log -\log$ graph. It is practically accepted that all fuses of an EDN have the same value of $a[3]$. In order to calculate $b$, first a three-phase fault is applied at the end of the protected lateral and the fault current of the fuse and the recloser is obtained. Then, the fuse operating time is calculated by [3]:

$$
t_{\text {fuse }}=t_{f-\text { recl }}+\frac{\left(t_{\text {s-recl }}-t_{f-r e c l}\right)}{2}
$$

where $t_{\text {f-recl }}$ and $t_{\text {s-recl }}$ are the recloser operating times of fast and slow modes, respectively, obtained by Equation (1). Constant $b$ is obtained using Equations (2) and (3).

\section{$3 \quad$ Proposed Recloser Characteristic}

With the programmable feature of microprocessor-based relays, in [17-21] non-standard characteristics are proposed to improve the EDN protection in the presence of DG units. However, the proposed characteristics are not suitable for fuse saving applications.

This paper proposes a new recloser characteristic that is able to maintain fuse-recloser coordination in EDNs with/without DG and does not require any communication link. The proposed characteristic is self-adaptive in the sense that it changes its setting by changes in voltage and current magnitudes at the recloser location.

The proposed characteristic for the fast operation of recloser is given by:

$$
t_{\text {recl }}=\left[\frac{28.2}{\left(\frac{I_{s c}}{I_{s e t}}\right)^{2}-\left(\frac{1}{e^{\left(1-V_{s c}\right)}}\right)^{2}}+0.1217\right] \times\left[V_{s c} \times\left(1-V_{s c}\right)\right] \times T D S
$$

where $T D S$ is the time dial setting, $I_{s c}$ is the recloser fault current, $I_{s e t}$ is the relay current setting, $V_{s c}$ is the recloser fault voltage in per-unit (p.u.), and $t_{\text {recl }}$ is the operating time of the recloser.

During a fault, the current passing through the recloser decreases whereas the fuse current increases due to the DG fault current contribution. As a result, in contrast to the case with no DG presence, the fault current at the recloser location decreases whilst the fuse fault current increases leading to loss of coordination between the recloser and its downstream fuses [2]. In addition, DG can keep voltage at its connection point and thus the voltage across the feeder can increase.

Figure 1 illustrates the proposed recloser characteristic with TDS set at 1 . The proposed relay has an inverse-time overcurrent characteristic in the current dimension and a voltage parabolic characteristic in the voltage dimension. When a fault occurs at the end of a feeder, the voltage dip at the recloser location is less than when the fault is nearer to the recloser. In addition, the recloser fault current in the latter case is higher. The proposed characteristic is designed to respond well to the fault behaviour of EDNs with/without DG. With the DG integration into the EDN, the voltage drop and fault current at the recloser location are less than the case without DG. The voltage parabolic characteristic is able to control the operating time of recloser in the presence of DG.

As it is shown in Figure 1, after a fault inception, the voltage has a reduction effect on the operating time of the recloser. Therefore, the proposed scheme uses the voltage magnitude as an indication of the fault location to modify the operating time of the recloser. For a fault close to the recloser, the voltage magnitude is low whereas for a fault at the remote end of the feeder, the voltage magnitude is high. After DG integration, the voltage magnitude at the recloser location can increase. On the other hand, 
DG has a negative effect on the fuse-recloser coordination due to changes in the fault currents of the recloser and fuse. By investigating the proposed characteristic in (4) using Figure 1, it is obvious that the effect of the voltage magnitude is carefully devised to tackle the fuse-recloser miscoordination, because the recloser operating time is reduced according to the voltage magnitude and a faster operation time is achieved for close and remote faults.

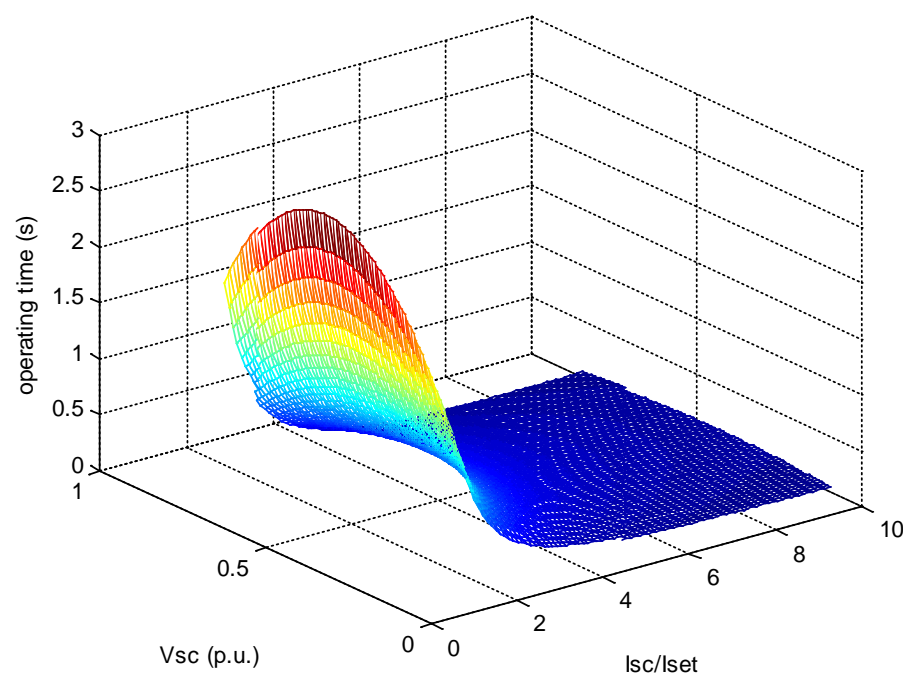

Figure 1. Proposed recloser characteristic with TDS=1.

\section{Test System}

In order to evaluate the effectiveness of the proposed scheme for the fuse saving strategy, an Iranian 20 $\mathrm{kV}$ distribution network is employed. Figure 2 shows the single-line diagram of the test system. It contains 19 fuses and it is energised by two $63 / 20 \mathrm{kV}, 15$ MVA power transformers with $5.8 \%$ transient reactance. Fault current at the $63 \mathrm{kV}$ level is $2.44 \mathrm{kA}$. Detailed information of the test EDN is given in Appendix.

Each synchronous generator has a capacity of 1.3 MVA and a sub-transient impedance of $13.6 \%$ and is connected to the EDN through a $0.4 / 20 \mathrm{kV}$ step-up transformer with $3 \%$ transient reactance.

The maximum load current through the recloser is $120.2 \mathrm{~A}$. $I_{\text {set }}$ for the recloser is set at 1.5 times the maximum load current [3], i.e. 180.3 A. TDSs of the recloser for slow and fast operations are set to 1.5 and 0.5 , respectively [3].

For the fuse modelling, it is assumed that all the fuses have the same " $a$ " parameter equals to -1.8 [3]. In order to obtain the " $b$ " parameter, a three-phase fault is applied at the end of the protected lateral and the fault current of the fuse and the recloser are obtained. Then constant $b$ is obtained using Equations (2) and (3). Table 1 summarises the values of the constant $b$ for all the fuses in the test system. The fuses are named as their respective line section.

Table 1. Fuse $b$ constant.

\begin{tabular}{llll}
\hline $\begin{array}{l}\text { Fuse } \\
\text { name }\end{array}$ & $\begin{array}{l}\text { constant } \\
\boldsymbol{b}\end{array}$ & $\begin{array}{l}\text { Fuse } \\
\text { name }\end{array}$ & $\begin{array}{l}\text { constant } \\
\boldsymbol{b}\end{array}$ \\
\hline F07 & 5.805 & F42 & 5.446 \\
F15 & 5.788 & F44 & 5.444 \\
F17 & 5.638 & F48 & 5.414 \\
F21 & 5.477 & F56 & 5.391 \\
\hline
\end{tabular}




\begin{tabular}{llll}
\hline F23 & 5.459 & F58 & 5.39 \\
F26 & 5.412 & F69 & 5.389 \\
F30 & 5.524 & F76 & 5.388 \\
F34 & 5.506 & F78 & 5.386 \\
F36 & 5.47 & F81 & 5.385 \\
F41 & 5.42 & & \\
\hline
\end{tabular}

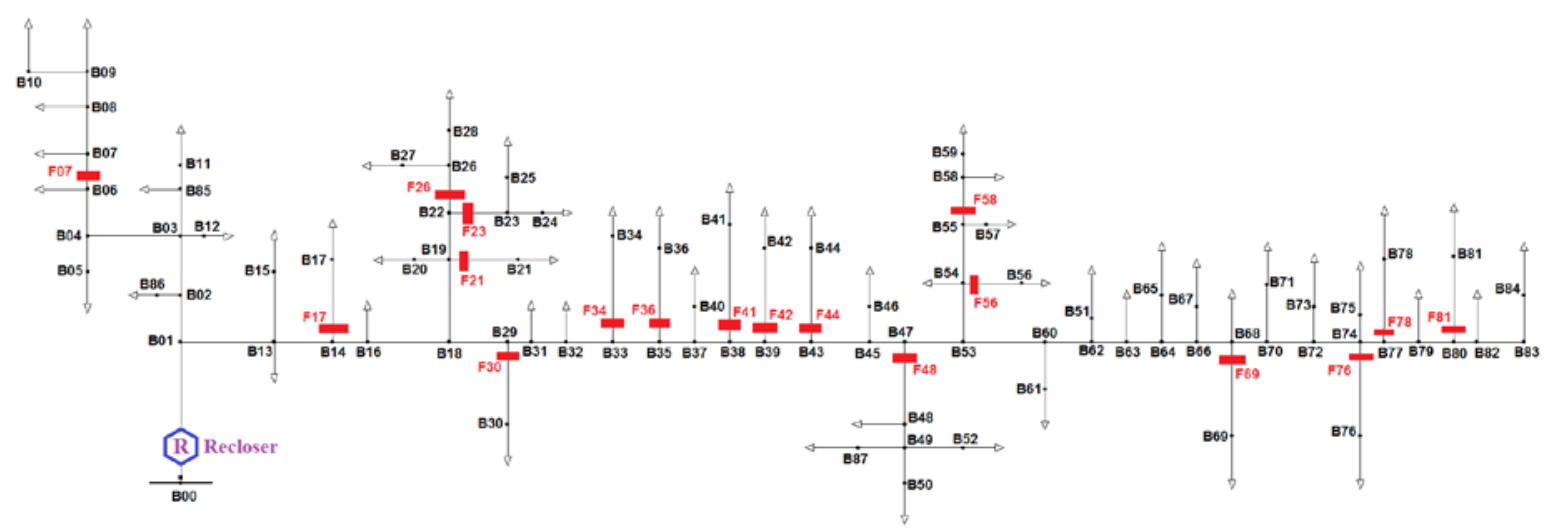

Figure 2. An Iranian $20 \mathrm{kV}$ electrical distribution network.

\section{$5 \quad$ Simulation Results}

The proposed recloser characteristic is compared with the standard characteristic in three different scenarios. First scenario is the EDN without any DG unit. Second scenario includes two DG units connected at B03 and B53. In the third scenario, the DG configuration is the same as the second scenario with the connection points at B03 and B83.

The fuse saving strategy should provide protection against all fault types including three-phase (LLL), double-phase (LL), double phase to earth (LLG) and single-phase to earth (LG) faults. In this study, all the fault types are applied at different locations and the performance of the proposed method is evaluated. The fault locations are at just downstream of each fuse. Therefore, the total number of fault locations is 19 and a set of all fault types is applied at each location. $I_{\text {set }}$ for the proposed characteristic is set at 180.3 , and its TDS is set at 2 .

Tables 2-4 show the simulation results of the proposed characteristic compared with the standard characteristic for different fault types of the test scenarios. In the Tables, t-fuse, t-std and t-p are the fuse operating time, the standard and the proposed recloser operating times, respectively. CTIstd and CTIp are the coordination time interval (CTI) between the recloser and fuse operation times for the standard method and the proposed method, respectively.

Table 2. Results of the conventional and proposed schemes for different fault types of the first scenario.

\begin{tabular}{lllllll}
\hline Fault type & Faulted line & t-fuse & t-std & t-p & CTIstd & CTIp \\
\hline \multirow{6}{*}{ LLL } & L07 & 0.296 & 0.102 & 0.102 & 0.19 & 0.19 \\
& L15 & 0.207 & 0.09 & 0.082 & 0.12 & 0.13 \\
& L17 & 0.258 & 0.115 & 0.114 & 0.14 & 0.14 \\
& L21 & 0.335 & 0.168 & 0.148 & 0.17 & 0.19 \\
& L23 & 0.368 & 0.184 & 0.156 & 0.18 & 0.21 \\
& L26 & 0.508 & 0.254 & 0.186 & 0.25 & 0.32 \\
\hline
\end{tabular}




\begin{tabular}{|c|c|c|c|c|c|c|}
\hline & L30 & 0.296 & 0.145 & 0.135 & 0.15 & 0.16 \\
\hline & L34 & 0.32 & 0.157 & 0.141 & 0.16 & 0.18 \\
\hline & L36 & 0.358 & 0.179 & 0.153 & 0.18 & 0.21 \\
\hline & L41 & 0.51 & 0.256 & 0.185 & 0.25 & 0.33 \\
\hline & L42 & 0.423 & 0.212 & 0.167 & 0.21 & 0.26 \\
\hline & L44 & 0.431 & 0.216 & 0.168 & 0.22 & 0.26 \\
\hline & L48 & 0.574 & 0.288 & 0.195 & 0.29 & 0.38 \\
\hline & L56 & 0.764 & 0.383 & 0.227 & 0.38 & 0.54 \\
\hline & L58 & 1.058 & 0.512 & 0.264 & 0.55 & 0.79 \\
\hline & L69 & 0.915 & 0.455 & 0.246 & 0.46 & 0.67 \\
\hline & L76 & 1.026 & 0.506 & 0.259 & 0.52 & 0.77 \\
\hline & L78 & 1.036 & 0.512 & 0.261 & 0.52 & 0.78 \\
\hline & L81 & 1.101 & 0.542 & 0.268 & 0.56 & 0.83 \\
\hline \multirow{19}{*}{ LL } & L07 & 0.383 & 0.115 & 0.109 & 0.27 & 0.27 \\
\hline & L15 & 0.267 & 0.099 & 0.097 & 0.17 & 0.17 \\
\hline & L17 & 0.333 & 0.132 & 0.12 & 0.2 & 0.21 \\
\hline & L21 & 0.433 & 0.201 & 0.148 & 0.23 & 0.29 \\
\hline & L23 & 0.476 & 0.223 & 0.154 & 0.25 & 0.32 \\
\hline & L26 & 0.657 & 0.316 & 0.177 & 0.34 & 0.48 \\
\hline & L30 & 0.384 & 0.171 & 0.141 & 0.21 & 0.24 \\
\hline & L34 & 0.414 & 0.186 & 0.149 & 0.23 & 0.27 \\
\hline & L36 & 0.463 & 0.215 & 0.161 & 0.25 & 0.3 \\
\hline & L41 & 0.66 & 0.313 & 0.196 & 0.35 & 0.46 \\
\hline & L42 & 0.547 & 0.256 & 0.178 & 0.29 & 0.37 \\
\hline & L44 & 0.557 & 0.261 & 0.18 & 0.3 & 0.38 \\
\hline & L48 & 0.742 & 0.353 & 0.21 & 0.39 & 0.53 \\
\hline & L56 & 0.988 & 0.475 & 0.243 & 0.51 & 0.75 \\
\hline & L58 & 1.368 & 0.639 & 0.28 & 0.73 & 1.09 \\
\hline & L69 & 1.184 & 0.563 & 0.268 & 0.62 & 0.92 \\
\hline & L76 & 1.327 & 0.627 & 0.283 & 0.7 & 1.04 \\
\hline & L78 & 1.341 & 0.635 & 0.285 & 0.71 & 1.06 \\
\hline & L81 & 1.425 & 0.672 & 0.293 & 0.75 & 1.13 \\
\hline \multirow{15}{*}{ LG } & L07 & 2.888 & 0.55 & 0.374 & 2.34 & 2.51 \\
\hline & L15 & 2.341 & 0.464 & 0.219 & 1.88 & 2.12 \\
\hline & L17 & 2.289 & 0.627 & 0.496 & 1.66 & 1.79 \\
\hline & L21 & 1.946 & 0.758 & 0.691 & 1.19 & 1.26 \\
\hline & L23 & 1.922 & 0.777 & 0.72 & 1.15 & 1.2 \\
\hline & L26 & 1.884 & 0.831 & 0.797 & 1.05 & 1.09 \\
\hline & L30 & 2.263 & 0.8 & 0.726 & 1.46 & 1.54 \\
\hline & L34 & 2.344 & 0.862 & 0.801 & 1.48 & 1.54 \\
\hline & L36 & 2.398 & 0.957 & 0.906 & 1.44 & 1.49 \\
\hline & L41 & 2.916 & 1.293 & 1.226 & 1.62 & 1.69 \\
\hline & L42 & 2.709 & 1.148 & 1.096 & 1.56 & 1.61 \\
\hline & L44 & 2.752 & 1.166 & 1.113 & 1.59 & 1.64 \\
\hline & L48 & 3.241 & 1.481 & 1.381 & 1.76 & 1.86 \\
\hline & L56 & 3.841 & 1.819 & 1.62 & 2.02 & 2.22 \\
\hline & L58 & 4.739 & 2.244 & 1.875 & 2.5 & 2.86 \\
\hline
\end{tabular}




\begin{tabular}{llllll}
\hline L69 & 4.581 & 2.205 & 1.87 & 2.38 & 2.71 \\
L76 & 4.999 & 2.412 & 1.988 & 2.59 & 3.01 \\
L78 & 5.046 & 2.435 & 2.001 & 2.61 & 3.05 \\
L81 & 5.278 & 2.556 & 2.066 & 2.72 & 3.21 \\
\hline
\end{tabular}

Table 3. Results of the conventional and proposed schemes for different fault types of the second scenario.

\begin{tabular}{|c|c|c|c|c|c|c|}
\hline Fault type & Faulted line & t-fuse & t-std & $t-p$ & CTIstd & CTIp \\
\hline \multirow{19}{*}{ LLL } & L07 & 0.256 & 0.108 & 0.108 & 0.15 & 0.15 \\
\hline & L15 & 0.173 & 0.093 & 0.086 & 0.08 & 0.09 \\
\hline & L17 & 0.217 & 0.123 & 0.122 & 0.09 & 0.1 \\
\hline & L21 & 0.278 & 0.193 & 0.165 & 0.09 & 0.11 \\
\hline & L23 & 0.308 & 0.216 & 0.177 & 0.09 & 0.13 \\
\hline & L26 & 0.438 & 0.322 & 0.22 & 0.12 & 0.22 \\
\hline & L30 & 0.233 & 0.16 & 0.147 & 0.07 & 0.09 \\
\hline & L34 & 0.245 & 0.174 & 0.155 & 0.07 & 0.09 \\
\hline & L36 & 0.258 & 0.2 & 0.168 & 0.06 & 0.09 \\
\hline & L41 & 0.373 & 0.31 & 0.217 & 0.06 & 0.16 \\
\hline & $\mathrm{L} 42$ & 0.289 & 0.239 & 0.186 & 0.05 & 0.1 \\
\hline & L44 & 0.293 & 0.244 & 0.188 & 0.05 & 0.11 \\
\hline & $\mathrm{L} 48$ & 0.369 & 0.34 & 0.227 & 0.03 & 0.14 \\
\hline & L56 & 0.513 & 0.499 & 0.284 & 0.01 & 0.23 \\
\hline & $\mathrm{L} 58$ & 0.752 & 0.745 & 0.356 & 0.01 & 0.4 \\
\hline & L69 & 0.646 & 0.638 & 0.324 & 0.01 & 0.32 \\
\hline & L76 & 0.739 & 0.737 & 0.351 & 0 & 0.39 \\
\hline & L78 & 0.747 & 0.75 & 0.355 & 0 & 0.39 \\
\hline & L81 & 0.802 & 0.812 & 0.371 & -0.01 & 0.43 \\
\hline \multirow{19}{*}{ LL } & L07 & 0.33 & 0.124 & 0.114 & 0.21 & 0.22 \\
\hline & L15 & 0.224 & 0.103 & 0.1 & 0.12 & 0.12 \\
\hline & L17 & 0.281 & 0.145 & 0.127 & 0.14 & 0.15 \\
\hline & L21 & 0.36 & 0.238 & 0.161 & 0.12 & 0.2 \\
\hline & L23 & 0.399 & 0.27 & 0.17 & 0.13 & 0.23 \\
\hline & L26 & 0.567 & 0.414 & 0.201 & 0.15 & 0.37 \\
\hline & L30 & 0.302 & 0.194 & 0.153 & 0.11 & 0.15 \\
\hline & L34 & 0.318 & 0.213 & 0.162 & 0.11 & 0.16 \\
\hline & L36 & 0.335 & 0.248 & 0.177 & 0.09 & 0.16 \\
\hline & L41 & 0.484 & 0.399 & 0.229 & 0.09 & 0.26 \\
\hline & L42 & 0.375 & 0.302 & 0.201 & 0.07 & 0.17 \\
\hline & L44 & 0.38 & 0.308 & 0.203 & 0.07 & 0.18 \\
\hline & L48 & 0.478 & 0.439 & 0.247 & 0.04 & 0.23 \\
\hline & L56 & 0.666 & 0.659 & 0.303 & 0.01 & 0.36 \\
\hline & L58 & 0.974 & 1.005 & 0.376 & -0.03 & 0.6 \\
\hline & L69 & 0.837 & 0.852 & 0.356 & -0.02 & 0.48 \\
\hline & L76 & 0.958 & 0.993 & 0.388 & -0.04 & 0.57 \\
\hline & L78 & 0.97 & 1.011 & 0.392 & -0.04 & 0.58 \\
\hline & L81 & 1.041 & 1.099 & 0.41 & -0.06 & 0.63 \\
\hline \multirow{3}{*}{ LG } & L07 & 2.84 & 0.703 & 0.469 & 2.14 & 2.37 \\
\hline & L15 & 2.302 & 0.579 & 0.265 & 1.72 & 2.04 \\
\hline & L17 & 2.23 & 0.825 & 0.637 & 1.41 & 1.59 \\
\hline
\end{tabular}




\begin{tabular}{llllll}
\hline L21 & 1.869 & 1.053 & 0.939 & 0.82 & 0.93 \\
L23 & 1.845 & 1.09 & 0.989 & 0.76 & 0.86 \\
L26 & 1.803 & 1.203 & 1.132 & 0.6 & 0.67 \\
L30 & 2.16 & 1.117 & 0.987 & 1.04 & 1.17 \\
L34 & 2.221 & 1.229 & 1.109 & 0.99 & 1.11 \\
L36 & 2.237 & 1.412 & 1.297 & 0.83 & 0.94 \\
L41 & 2.694 & 2.074 & 1.908 & 0.62 & 0.79 \\
L42 & 2.486 & 1.784 & 1.652 & 0.7 & 0.83 \\
L44 & 2.521 & 1.821 & 1.686 & 0.7 & 0.84 \\
L48 & 2.905 & 2.518 & 2.271 & 0.39 & 0.63 \\
L56 & 3.437 & 3.349 & 2.863 & 0.09 & 0.57 \\
L58 & 4.258 & 4.547 & 3.587 & -0.29 & 0.67 \\
L69 & 4.125 & 4.345 & 3.489 & -0.22 & 0.64 \\
L76 & 4.509 & 4.953 & 3.832 & -0.44 & 0.68 \\
L78 & 4.552 & 5.026 & 3.872 & -0.47 & 0.68 \\
L81 & 4.766 & 5.406 & 4.073 & -0.64 & 0.69 \\
\hline
\end{tabular}

Table 4. Results of the conventional and proposed schemes for different fault types of the third scenario.

\begin{tabular}{|c|c|c|c|c|c|c|}
\hline Fault type & Faulted line & t-fuse & t-std & $t-p$ & CTIstd & CTIp \\
\hline \multirow{19}{*}{ LLL } & L07 & 0.257 & 0.108 & 0.108 & 0.15 & 0.15 \\
\hline & L15 & 0.174 & 0.093 & 0.086 & 0.08 & 0.09 \\
\hline & $\mathrm{L} 17$ & 0.219 & 0.123 & 0.122 & 0.1 & 0.1 \\
\hline & L21 & 0.281 & 0.192 & 0.165 & 0.09 & 0.12 \\
\hline & $\mathrm{L} 23$ & 0.312 & 0.215 & 0.177 & 0.1 & 0.14 \\
\hline & L26 & 0.442 & 0.32 & 0.22 & 0.12 & 0.22 \\
\hline & L30 & 0.237 & 0.16 & 0.147 & 0.08 & 0.09 \\
\hline & L34 & 0.25 & 0.174 & 0.154 & 0.08 & 0.1 \\
\hline & L36 & 0.264 & 0.2 & 0.168 & 0.06 & 0.1 \\
\hline & L41 & 0.382 & 0.309 & 0.217 & 0.07 & 0.17 \\
\hline & L42 & 0.297 & 0.239 & 0.186 & 0.06 & 0.11 \\
\hline & L44 & 0.301 & 0.244 & 0.188 & 0.06 & 0.11 \\
\hline & $\mathrm{L} 48$ & 0.381 & 0.339 & 0.227 & 0.04 & 0.15 \\
\hline & $\mathrm{L} 56$ & 0.529 & 0.496 & 0.282 & 0.03 & 0.25 \\
\hline & $\mathrm{L} 58$ & 0.771 & 0.737 & 0.353 & 0.03 & 0.42 \\
\hline & L69 & 0.497 & 0.552 & 0.297 & -0.06 & 0.2 \\
\hline & L76 & 0.532 & 0.621 & 0.317 & -0.09 & 0.22 \\
\hline & $\mathrm{L} 78$ & 0.537 & 0.631 & 0.32 & -0.09 & 0.22 \\
\hline & L81 & 0.556 & 0.673 & 0.332 & -0.12 & 0.22 \\
\hline \multirow{10}{*}{ LL } & L07 & 0.332 & 0.124 & 0.114 & 0.21 & 0.22 \\
\hline & L15 & 0.226 & 0.103 & 0.1 & 0.12 & 0.13 \\
\hline & L17 & 0.283 & 0.144 & 0.127 & 0.14 & 0.16 \\
\hline & L21 & 0.364 & 0.238 & 0.162 & 0.13 & 0.2 \\
\hline & L23 & 0.404 & 0.269 & 0.17 & 0.14 & 0.23 \\
\hline & L26 & 0.573 & 0.412 & 0.202 & 0.16 & 0.37 \\
\hline & L30 & 0.307 & 0.193 & 0.153 & 0.11 & 0.15 \\
\hline & L34 & 0.324 & 0.212 & 0.162 & 0.11 & 0.16 \\
\hline & L36 & 0.343 & 0.248 & 0.177 & 0.1 & 0.17 \\
\hline & L41 & 0.495 & 0.397 & 0.23 & 0.1 & 0.27 \\
\hline
\end{tabular}




\begin{tabular}{|c|c|c|c|c|c|c|}
\hline & L42 & 0.385 & 0.302 & 0.201 & 0.08 & 0.18 \\
\hline & L44 & 0.391 & 0.308 & 0.203 & 0.08 & 0.19 \\
\hline & L48 & 0.494 & 0.439 & 0.247 & 0.06 & 0.25 \\
\hline & L56 & 0.686 & 0.656 & 0.303 & 0.03 & 0.38 \\
\hline & L58 & 0.999 & 0.994 & 0.376 & 0.01 & 0.62 \\
\hline & L69 & 0.646 & 0.734 & 0.332 & -0.09 & 0.31 \\
\hline & L76 & 0.691 & 0.829 & 0.356 & -0.14 & 0.34 \\
\hline & L78 & 0.698 & 0.844 & 0.359 & -0.15 & 0.34 \\
\hline & L81 & 0.723 & 0.903 & 0.373 & -0.18 & 0.35 \\
\hline \multirow{19}{*}{ LG } & L07 & 2.84 & 0.698 & 0.467 & 2.14 & 2.37 \\
\hline & L15 & 2.301 & 0.575 & 0.263 & 1.73 & 2.04 \\
\hline & L17 & 2.23 & 0.817 & 0.632 & 1.41 & 1.6 \\
\hline & L21 & 1.87 & 1.041 & 0.929 & 0.83 & 0.94 \\
\hline & L23 & 1.846 & 1.077 & 0.978 & 0.77 & 0.87 \\
\hline & L26 & 1.805 & 1.189 & 1.12 & 0.62 & 0.69 \\
\hline & L30 & 2.161 & 1.102 & 0.975 & 1.06 & 1.19 \\
\hline & L34 & 2.223 & 1.211 & 1.095 & 1.01 & 1.13 \\
\hline & L36 & 2.24 & 1.387 & 1.276 & 0.85 & 0.96 \\
\hline & L41 & 2.699 & 2.031 & 1.872 & 0.67 & 0.83 \\
\hline & L42 & 2.491 & 1.746 & 1.62 & 0.75 & 0.87 \\
\hline & L44 & 2.526 & 1.782 & 1.653 & 0.74 & 0.87 \\
\hline & L48 & 2.913 & 2.451 & 2.215 & 0.46 & 0.7 \\
\hline & L56 & 3.448 & 3.252 & 2.787 & 0.2 & 0.66 \\
\hline & L58 & 4.272 & 4.403 & 3.485 & -0.13 & 0.79 \\
\hline & L69 & 3.871 & 4.394 & 3.562 & -0.52 & 0.31 \\
\hline & L76 & 4.162 & 5.073 & 3.971 & -0.91 & 0.19 \\
\hline & L78 & 4.197 & 5.153 & 4.016 & -0.96 & 0.18 \\
\hline & L81 & 4.354 & 5.585 & 4.263 & -1.23 & 0.09 \\
\hline
\end{tabular}

\section{Discussion}

As can be seen in Table 2, the minimum, average, and maximum difference between the standard recloser and the proposed recloser operation times in the EDN without DG are 0, 0.14, and 0.49 seconds, respectively. The maximum time difference is for LG fault occurring at the end of the feeder L81, and the minimum time difference is for the faults near to the recloser location. Therefore, it can be concluded that the proposed recloser characteristic has almost the same operation with the standard characteristic when the EDN is without DG.

The minimum CTI between the recloser and fuse operation times in the second scenario for the proposed self-adaptive scheme is 0.09 second, whilst this value for the standard scheme is -0.64 second. Negative CTI means that the fuse operate before the fast operation of the recloser. Also, the minimum CTI in the third scenario for the self-adaptive and standard schemes are 0.09 and -1.23 seconds, respectively. It is obvious that the proposed recloser characteristic is capable of providing fuse saving against all fault types.

In the presence of DG, it is impossible to have fuse saving using the standard characteristic as the recloser cannot operate for some fault locations and fault types before the fuse as shown by negative CTIs in Tables 3 and 4, whereas a proper coordination between the recloser and the fuse for all fault conditions is achieved by the proposed reclose characteristic for all fault conditions.

As shown in the results, if the fault occurs at remote ends of the EDN, the miscoordination between the fuse and the recloser is more likely. In addition, by comparing the results of the second and third scenarios, when DG is connected at the end of the feeder, the fuse saving is more unlikely because of 
more decreases in the recloser fault current. However, implementation of the proposed method modifies the recloser operating time according to the voltage parabolic characteristic.

It is conclusive that with the changes in fault conditions and DG configuration, the proposed selfadaptive scheme can maintain the fuse-recloser coordination, but the standard scheme is unable to prevent the fuse blowing under transient faults.

\section{$7 \quad$ Conclusion}

This paper proposes a new self-adaptive operating characteristic of reclosers for fuse saving in electrical distribution networks in the presence of DG units. The new recloser characteristic uses only local voltage and current magnitudes for the fuse saving task while the standard characteristic fails in the presence of DG. Unlike most previous adaptive fuse saving methods, the proposed characteristic does not require any communication link and different measurement points. The self-adaptive method is able to keep fuse saving against different fault types and locations. Moreover, it is shown in a comparative study that the method can maintain the coordination for high DG penetration levels and can overcome shortcomings of the conventional methods for the fuse-saving strategy. In addition, the method is simple and cost effective when compared with recent methods which require costly communication links.

\section{References}

1. T. A. Short, Electric Power Distribution Handbook: CRC Press, 2003.

2. M. H. Bollen, Integration of Distributed Generation in the Power System: John Wiley \& Sons, 2011.

3. A. F. Naiem, Y. Hegazy, A. Y. Abdelaziz, and M. A. Elsharkawy, "A Classification Technique for Recloser-Fuse Coordination in Distribution Systems With Distributed Generation," IEEE Transactions on Power Delivery, vol. 27, pp. 176-185, 2012

4. H. A. Abdel-Ghany, A. M. Azmy, N. I. Elkalashy, and E. M. Rashad, "Optimizing DG penetration in distribution networks concerning protection schemes and technical impact," Electric Power Systems Research, vol. 128, pp. 113-122, 11// 2015.

5. J. K. Tailor and A. H. Osman, "Restoration of fuse-recloser coordination in distribution system with high DG penetration," in 2008 IEEE Power and Energy Society General Meeting - Conversion and Delivery of Electrical Energy in the 21st Century, 2008, pp. 1-8.

6. B. Hussain, S. M. Sharkh, S. Hussain, and M. A. Abusara, "An Adaptive Relaying Scheme for Fuse saving in Distribution Networks With Distributed Generation," IEEE Transactions on Power Delivery, vol. 28, pp. 669-677, 2013.

7. J. Hyung-Chul, J. Sung-Kwan, and L. Kisung, "Optimal Placement of Superconducting Fault Current Limiters (SFCLs) for Protection of an Electric Power System with Distributed Generations (DGs)," IEEE Transactions on Applied Superconductivity, vol. 23, pp. 5600304-5600304, 2013.

8. L. Sung-Hun and K. Jae-Chul, "Analysis on Protection Coordination of Protective Devices With a SFCL Due to the Application Location of a Dispersed Generation in a Power Distribution System," IEEE Transactions on Applied Superconductivity, vol. 22, pp. 5601104-5601104, 2012.

9. H. H. Zeineldin and E. F. El-Saadany, "Fault current limiters to mitigate recloserfuse miscoordination with Distributed Genertion," in Managing the Change, 10th IET International Conference on Developments in Power System Protection (DPSP), 2010, pp. 1-4.

10. A. Elmitwally, E. Gouda, and S. Eladawy, "Restoring recloser-fuse coordination by optimal fault current limiters planning in DG-integrated distribution systems," International Journal of Electrical Power \& Energy Systems, vol. 77 , pp. 9-18, 5// 2016.

11. H. Yazdanpanahi, X. Wilsun, and L. Yun Wei, "A Novel Fault Current Control Scheme to Reduce Synchronous DG's Impact on Protection Coordination," IEEE Transactions on Power Delivery, vol. 29, pp. 542-551, 2014.

12. N. Rajaei and M. M. A. Salama, "Management of Fault Current Contribution of Synchronous DGs Using Inverter-Based DGs," IEEE Transactions on Smart Grid, vol. 6, pp. 3073-3081, 2015. 
13. P. H. Shah and B. R. Bhalja, "New adaptive digital relaying scheme to tackle recloser-fuse miscoordination during distributed generation interconnections," IET Generation, Transmission \& Distribution, vol. 8, pp. 682688, 2014 .

14. A. Zamani, T. Sidhu, and A. Yazdani, "A strategy for protection coordination in radial distribution networks with distributed generators," in IEEE Power and Energy Society General Meeting, 2010, pp. 1-8.

15. S. M. Brahma and A. A. Girgis, "Microprocessor-based reclosing to coordinate fuse and recloser in a system with high penetration of distributed generation," in IEEE Power Engineering Society Winter Meeting, 2002, pp. 453458 vol.1.

16. "IEEE Standard Inverse-Time Characteristic Equations for Overcurrent Relays," IEEE Std C37.112-1996, p. i, 1997.

17. S. Jamali and H. Borhani-Bahabadi. (2016, Recloser time-current-voltage characteristic for fuse saving in distribution networks with DG. IET Generation, Transmission \&amp; Distribution. Available: http://digitallibrary.theiet.org/content/journals/10.1049/iet-gtd.2016.0979

18. H. M. Sharaf, H. H. Zeineldin, D. K. Ibrahim, and E. E. L. D. A. El-Zahab, "A proposed coordination strategy for meshed distribution systems with DG considering user-defined characteristics of directional inverse time overcurrent relays," International Journal of Electrical Power \& Energy Systems, vol. 65, pp. 49-58, 2// 2015.

19. C. A. Castillo Salazar, A. Conde Enríquez, and S. E. Schaeffer, "Directional overcurrent relay coordination considering non-standardized time curves," Electric Power Systems Research, vol. 122, pp. 42-49, 5// 2015.

20. M. Dewadasa, A. Ghosh, G. Ledwich, and M. Wishart, "Fault isolation in distributed generation connected distribution networks," IET Generation, Transmission \& Distribution, vol. 5, pp. 1053-1061, 2011.

21. T. Keil and J. Jager, "Advanced Coordination Method for Overcurrent Protection Relays Using Nonstandard Tripping Characteristics," IEEE Transactions on Power Delivery, vol. 23, pp. 52-57, 2008.

\section{Appendix: Test System Data}

Detailed information about the test EDN is given in the Table 5. In Table 5, each load is connected at the receiving end of the line and average power factor for all loads is 0.9 lag.

Table 5. Lines and load data of test EDN.

\begin{tabular}{llllll|llllll}
\hline $\begin{array}{l}\text { Line } \\
\text { Name }\end{array}$ & From & To & $\mathbf{R}(\boldsymbol{\Omega})$ & $\mathbf{X}(\boldsymbol{\Omega})$ & $\begin{array}{l}\text { Load } \\
(\mathbf{k V A})\end{array}$ & $\begin{array}{l}\text { Line } \\
\text { Name }\end{array}$ & From & To & $\mathbf{R}(\boldsymbol{\Omega})$ & $\mathbf{X}(\boldsymbol{\Omega})$ & $\begin{array}{l}\text { Load } \\
(\mathbf{k V A})\end{array}$ \\
\hline L01 & B00 & B01 & 0.155 & 0.197 & 0 & L45 & B43 & B45 & 0.597 & 0.761 & 0 \\
L02 & B01 & B02 & 0.141 & 0.180 & 0 & L46 & B45 & B46 & 0.031 & 0.012 & 75.5 \\
L03 & B02 & B03 & 0.098 & 0.125 & 0 & L47 & B45 & B47 & 0.130 & 0.166 & 0 \\
L04 & B03 & B04 & 0.454 & 0.369 & 0 & L48 & B47 & B48 & 0.391 & 0.317 & 23.6 \\
L05 & B04 & B05 & 0.036 & 0.030 & 118 & L49 & B48 & B49 & 0.023 & 0.018 & 0 \\
L06 & B04 & B06 & 0.254 & 0.207 & 377.6 & L50 & B49 & B50 & 0.327 & 0.266 & 94.4 \\
L07 & B06 & B07 & 0.054 & 0.044 & 377.6 & L51 & B49 & B87 & 0.073 & 0.059 & 11.8 \\
L08 & B07 & B08 & 0.772 & 0.627 & 47.2 & L52 & B49 & B52 & 0.073 & 0.059 & 118 \\
L09 & B08 & B09 & 0.182 & 0.148 & 94.4 & L53 & B47 & B53 & 0.119 & 0.152 & 0 \\
L10 & B09 & B10 & 0.272 & 0.221 & 47.2 & L54 & B53 & B54 & 1.199 & 0.974 & 23.6 \\
L11 & B03 & B85 & 0.043 & 0.055 & 148.7 & L55 & B54 & B55 & 1.430 & 1.162 & 0 \\
L12 & B03 & B12 & 0.054 & 0.044 & 23.6 & L56 & B54 & B56 & 0.354 & 0.288 & 47.2 \\
L13 & B01 & B13 & 0.255 & 0.325 & 23.6 & L57 & B55 & B57 & 0.032 & 0.026 & 75.5 \\
L14 & B13 & B14 & 0.391 & 0.498 & 0 & L58 & B55 & B58 & 0.454 & 0.369 & 118 \\
L15 & B13 & B15 & 0.376 & 0.148 & 47.2 & L59 & B58 & B59 & 0.036 & 0.030 & 23.6 \\
L16 & B14 & B16 & 0.060 & 0.076 & 47.2 & L60 & B53 & B60 & 0.027 & 0.035 & 0 \\
L17 & B14 & B17 & 0.654 & 0.531 & 47.2 & L61 & B60 & B61 & 0.055 & 0.022 & 94.4 \\
L18 & B16 & B18 & 0.391 & 0.498 & 0 & L62 & B60 & B62 & 0.721 & 0.920 & 0 \\
L19 & B18 & B19 & 1.308 & 0.516 & 0 & L63 & B62 & B63 & 0.502 & 0.640 & 118 \\
\hline
\end{tabular}




\begin{tabular}{|c|c|c|c|c|c|c|c|c|c|c|c|}
\hline L20 & B19 & B20 & 0.125 & 0.049 & 47.2 & L64 & B63 & B64 & 0.366 & 0.467 & 0 \\
\hline L21 & B19 & B21 & 0.363 & 0.295 & 47.2 & L65 & B64 & B65 & 0.082 & 0.066 & 23.6 \\
\hline L22 & B19 & B22 & 0.462 & 0.182 & 0 & L66 & B64 & B66 & 0.054 & 0.069 & 0 \\
\hline L23 & B22 & B23 & 0.334 & 0.271 & 0 & $\mathrm{~L} 67$ & B66 & B67 & 0.059 & 0.048 & 47.2 \\
\hline L24 & B23 & B24 & 0.307 & 0.249 & 47.2 & L68 & B66 & B68 & 0.122 & 0.156 & 23.6 \\
\hline L25 & B24 & B25 & 0.318 & 0.258 & 47.2 & L69 & B68 & B69 & 0.136 & 0.111 & 94.4 \\
\hline L26 & B22 & B26 & 1.973 & 0.779 & 0 & L70 & B68 & B70 & 0.108 & 0.138 & 0 \\
\hline L27 & B26 & B27 & 0.133 & 0.053 & 23.6 & L71 & B70 & B71 & 0.091 & 0.074 & 23.6 \\
\hline L28 & B26 & B28 & 0.415 & 0.164 & 47.2 & L72 & B70 & B72 & 0.244 & 0.311 & 0 \\
\hline L29 & B18 & B29 & 0.325 & 0.415 & 0 & L73 & B72 & B73 & 0.188 & 0.074 & 148.7 \\
\hline L30 & B29 & B30 & 0.472 & 0.384 & 23.6 & L74 & B72 & B74 & 0.098 & 0.125 & 0 \\
\hline L31 & B29 & B31 & 0.027 & 0.035 & 23.6 & L75 & B74 & B75 & 0.211 & 0.083 & 47.2 \\
\hline L32 & B31 & B32 & 0.176 & 0.225 & 23.6 & L76 & B74 & B76 & 0.136 & 0.111 & 94.4 \\
\hline L33 & B32 & B33 & 0.054 & 0.069 & 0 & L77 & B74 & B77 & 0.027 & 0.035 & 0 \\
\hline L34 & B33 & B34 & 0.416 & 0.338 & 35.4 & L78 & B77 & B78 & 0.173 & 0.140 & 23.6 \\
\hline L35 & B33 & B35 & 0.521 & 0.664 & 0 & L79 & B77 & B79 & 0.136 & 0.173 & 7.1 \\
\hline L36 & B35 & B36 & 0.313 & 0.124 & 23.6 & L80 & B79 & B80 & 0.114 & 0.145 & 0 \\
\hline L37 & B35 & B37 & 0.187 & 0.239 & 0 & L81 & B80 & B81 & 0.182 & 0.148 & 47.2 \\
\hline L38 & B37 & B38 & 0.187 & 0.239 & 0 & L82 & B80 & B82 & 0.024 & 0.031 & 23.6 \\
\hline L39 & B38 & B39 & 0.187 & 0.239 & 0 & L83 & B82 & B83 & 0.069 & 0.088 & 0 \\
\hline L40 & B37 & B40 & 0.125 & 0.049 & 47.2 & L84 & B83 & B84 & 0.182 & 0.148 & 23.6 \\
\hline L41 & B38 & B41 & 1.135 & 0.923 & 47.2 & L85 & B85 & B11 & 0.036 & 0.030 & 297.4 \\
\hline L42 & B39 & B42 & 0.145 & 0.118 & 148.7 & L86 & B02 & B86 & 0.023 & 0.018 & 297.4 \\
\hline L43 & B39 & B43 & 0.054 & 0.069 & 0 & L87 & B51 & B62 & 0.023 & 0.018 & 0 \\
\hline L44 & B43 & B44 & 0.145 & 0.118 & 23.6 & & & & & & \\
\hline
\end{tabular}

